\title{
Whole exome sequencing reveals a novel LRBA mutation and clonal hematopoiesis in a common variable immunodeficiency patient presented with hemophagocytic lymphohistiocytosis
}

Yanling Ren ${ }^{1,2}$, Feng Xiao ${ }^{2}$, Fei Cheng ${ }^{3}$, Xin Huang ${ }^{2}$, Jianhu Li ${ }^{2}$, Xiaogang Wang ${ }^{4}$, Wei Lang ${ }^{2}$, Xinping Zhou ${ }^{1,2}$, Jianping Lan ${ }^{4^{*}}$ and Hongyan Tong ${ }^{1,2^{*}}$

\begin{abstract}
Common variable immunodeficiency (CVID) was a kind of primary immunodeficiency disorders with heterogeneous phenotype and genotype. Lipopolysaccharide-responsive and beige-like anchor (LRBA) mutation was identified as disease associated in CVID, advanced genetic method will help to detect atypical cases. We report a case of adult patient manifested as hemophagocytic lymphohistiocytosis $(\mathrm{HLH})$, bone marrow examination suggested prosperity to MDS, manifested as increased immature myeloid cells and dysplastic hematopoiesis. Whole exome sequencing (WES) identified a novel heterogeneous c.1876T > C (p.W626R) mutation in LRBA and four somatic mutations: ASXL1 (c.1967dupA); PTPN11 (c.226G > A), U2AF1 (c.101C > T and c.470A > G), among which ASXL1 was a high-risk marker of clonal hematopoiesis. Combined with her recurrent severe infections and immune abnormalities such as hypoimmunoglobulinemia, the patient was diagnosed with CVID. Subsequent hematopoietic stem cell transplantation saved her from severe cytopenia and immune deficiency. This case report highlights the great promise of utilization of WES for diagnosing rare disease with atypical manifestations and guiding further treatment.
\end{abstract}

Keywords: Common variable immunodeficiency, LPS-responsive beige-like anchor, Hemophagocytic lymphohistiocytosis, Myeloid malignancy, Hematopoietic stem cell transplantation

Letter to the Editor,

Hemophagocytic lymphohistiocytosis (HLH) is a rapidly progressing and highly fatal disease, and the prognosis is closely related to the treatment of the primary disease [1],

\footnotetext{
*Correspondence: lanjp@163.com; tonghongyan@zju.edu.cn

${ }^{1}$ Myelodysplastic Syndromes Diagnosis and Therapy Center, Department of Hematology, The First Affiliated Hospital, College of Medicine, Zhejiang University, 79\# Qingchun Road, Hangzhou 310003, Zhejiang, China

${ }^{4}$ Department of Hematology and Hematopoietic Stem Cell Transplant

Center, Zhejiang Provincial People's Hospital, Hangzhou 310014, Zhejiang, China

Full list of author information is available at the end of the article
}

so it is particularly important to actively search for the cause while treating HLH. Common variable immunodeficiency (CVID) is the most prevalent primary immunodeficiency disorder with heterogeneous phenotype and genotype [2], a timely and accurate diagnosis is also urgent to prevent significant morbidity and mortality [3]. Here, we report an adult CVID patient manifested as HLH, whole exome sequencing (WES) revealed LPSresponsive beige-like anchor (LRBA) and myeloid malignancy associated mutations may be the genetic cause. Finally, hematopoietic stem cell transplantation (HSCT) saved her from severe cytopenia and immune deficiency.

c) The Author(s) 2021. This article is licensed under a Creative Commons Attribution 4.0 International License, which permits use, sharing, adaptation, distribution and reproduction in any medium or format, as long as you give appropriate credit to the original author(s) and the source, provide a link to the Creative Commons licence, and indicate if changes were made. The images or other third party material in this article are included in the article's Creative Commons licence, unless indicated otherwise in a credit line to the material. If material is not included in the article's Creative Commons licence and your intended use is not permitted by statutory regulation or exceeds the permitted use, you will need to obtain permission directly from the copyright holder. To view a copy of this licence, visit http://creativeco mmons.org/licenses/by/4.0/. The Creative Commons Public Domain Dedication waiver (http://creativecommons.org/publicdomain/ zero/1.0/) applies to the data made available in this article, unless otherwise stated in a credit line to the data. 
A 46 years old female patient who presented with fever and fatigue as well as cytopenia for 20 days was referred to our center, physical examinations showed significantly hepatosplenomegaly. Laboratory tests revealed low fibrinogen and elevated ferritin and soluble CD25. Bone marrow smear showed an increase of phagocytosis (Fig 1A). Flow cytometry showed increased abnormal granulocytes of $76.45 \%$ (Fig 1B), while biopsy showed proliferative hematopoiesis with dysplastic erythroid and increased immature cells (Fig 1C). Hypogammaglobinemia and abnormal $\mathrm{T}$ cell subpopulations of peripheral blood were also detected (Table 1). Image test suggested pneumonia but no evidence of malignancy (Additional file 1: Figure S1). Therefore, the diagnosis of HLH is established. Viral infections were excluded by negative serology results. Her previous history showed recurrent respiratory tract infection, severe human papilloma virus infection led to total hysterectomy and severe virus pneumonia which needed ventilator adjuvant treatment. Unexplained hepatosplenomegaly and hypogammaglobinemia was found then, but no severe cytopenia, thus CVID was established. WES analysis detected a novel single heterozygous mutation of $L R B A$ (c.1876T > C; p.W626R). Another 4 somatic mutations which suggested clonal hematopoiesis were also identified: ASXL1(c.1967dupA); PTPN11(c.226G > A); $U 2 A F 1$ (c.101C $>$ T and c.470A $>$ G). After obtaining the informed consent, the same mutation of $L R B A$ in her healthy father, little brother and her son were confirmed by Sanger sequencing, but no such mutation in her mother and the older brother (Fig 1D).
According to the HLH-2004 protocol, glucocorticoid and etoposide was given to her. Her fever improved and the spleen was significantly shrinked, but she still had cytopenia. On July 14th 2020, she underwent haploindentical allogeneic HSCT from her older brother. Until the time of writing this article, the patient showed normal blood cell count, close to normal immunoglobulin except for low IGA, no mutations were detected for another WES analysis.

Homozygous and compound heterozygous mutations of $L R B A$ were identified as one cause of CVID recently, which could decrease or abolish LRBA protein expression, thus resulting in very low cytotoxic $\mathrm{T}$ lymphocyte-associated antigen 4 (CTLA4) expression and dysfunction of T cells [4]. Some researchers believed that mild phenotypes were associated with compound heterozygous mutations and residual protein expression of LRBA, while other research showed that LRBA protein expression levels are not correlated with clinical phenotypes $[5,6]$.Unfortunately, we have not tested the protein expression of LRBA in time, the T-to-C transition at position c.1876 in exon 14 of $L R B A$ caused a substitution at position p. W626R(Cosmic 8925453), which was not in the main functional structural regions of the protein and we speculated that the novel mutation may be associated with LRBA structural instability and damaged regulatory function, just as reported by Pauline A et al., monoallelic LRBA mutation was disease associated [7]. Besides, possible polygenic and epigenetic factors could also involve in CVID pathogenesis, including PTPN11 [8, 9]. Just as in our case,

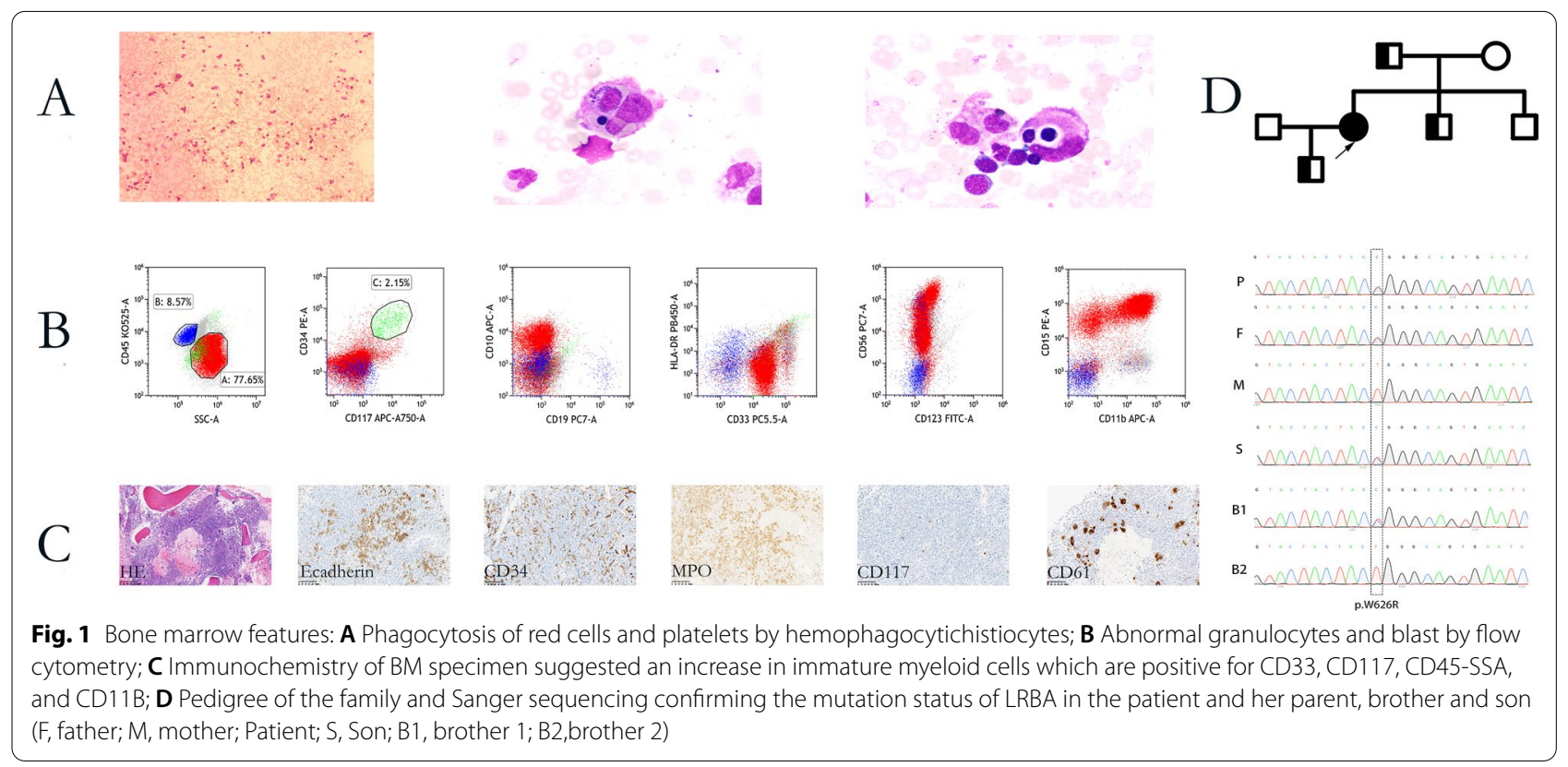


Table 1 Immunological parameters

\begin{tabular}{|c|c|c|c|}
\hline Parameters & Measurement at diagnosis & Measurement after HSCT (4 months) & Normal range \\
\hline Hemoglobin, $g / L$ & 57 & 110 & $115-150$ \\
\hline Platlet,$\times 10^{9} / \mathrm{L}$ & 5 & 133 & $100-300$ \\
\hline Leucocytes, $\times 10^{9} / \mathrm{L}$ & 7.5 & 4.5 & $4-9$ \\
\hline Lymphocytes, $\times 10^{9} / \mathrm{L}$ & 0.67 & 1.8 & $1.1-3.2$ \\
\hline B cells, \% & 2.8 & 7.26 & $5.1-20.3$ \\
\hline T cells & 95.2 & 86.74 & $53.7-80.9$ \\
\hline $\mathrm{CD}^{+} \mathrm{CD}^{+}, \%$ & 19.9 & 14.8 & $19.57-48.02$ \\
\hline $\mathrm{CD}^{+} \mathrm{CD}^{+}, \%$ & 75.3 & 71.94 & $15.8-37.5$ \\
\hline $\mathrm{CD}^{+}{ }^{+} \mathrm{CD} 25^{+} \mathrm{FOXP}_{3}^{+}, \%$ & 0.23 & 0.49 & $1.11-2.9$ \\
\hline NK cell, \% & 2.0 & 6 & $6.7-30.9$ \\
\hline Total T/NK lymphocyte, \% & 8.96 & 16.94 & $17.06-43.35$ \\
\hline Cytotoxic T/NK Lymphocyte,\% & 2.29 & 3.73 & $2.86-18.22$ \\
\hline Non-Cytotoxic T/NK Lymphocyte,\% & 6.68 & 13.21 & $11.15-35.76$ \\
\hline IGG, mg/dL & 543 & 1160 & $860-1740$ \\
\hline IGA, mg/dL & 10 & 79 & $100-420$ \\
\hline IGM, mg/dL & 18 & 123 & $50-280$ \\
\hline $\mathrm{C} 3, \mathrm{mg} / \mathrm{dL}$ & 78 & 124 & $70-140$ \\
\hline $\mathrm{C} 4, \mathrm{mg} / \mathrm{dL}$ & 19 & 36 & $10-40$ \\
\hline $\mathrm{sCd} 25, \mathrm{pg} / \mathrm{ml}$ & 22914 & 5367 & $<6400$ \\
\hline NK cytotoxicity & $22.96 \%$ & $17.44 \%$ & $\geq 15.11 \%$ \\
\hline
\end{tabular}

mutations of ASXL1, U2AF1 and PTPN11 combined with $L R B A$ may participate in the formation of clinical phenotype. Importantly, CVID patients had a higher risk of developing malignancies, mainly lymphoma, MDS were rarely reported [10]. Increased immature cells and dysplastic hematopoiesis as well as the detection of clonal marker such as mutations in ASXL1 and $U 2 A F$ all suggested the diagnosis for MDS [11]. Moreover, after HLH had been effectively controlled, cytopenia was not improved, all prompting us to perform HSCT as soon as possible.

In conclusion, we report a rare case of patient with CVID manifested as HLH had LRBA mutation and clonal hematopoiesis. WES played an important role in etiology diagnosis and guiding treatment, thus should be considered in patients with atypical manifestations.

\section{Supplementary Information}

The online version contains supplementary material available at https://doi. org/10.1186/s40164-021-00229-y.

Additional file 1: Figure S1. A Scattered inflammation of both lungs and pleural effusion by chest CT scan. B PET-CT demonstrated enlargement of the spleen, mild increased FDG in the bone marrow and sinusitis.

Acknowledgements

Not applicable.

\section{Authors' contributions}

YLR conceived the study, analyzed data, and drafted the manuscript. WL analyzed data. FC, XH and JHL collected and interpreted the data, XGW and XPZ followed the patient. JPL and HYT reviewed the manuscript. All authors read and approved the final manuscript.

\section{Funding}

This work was supported by the National Natural Science Foundation of China grants $(81700121,81970117)$.

\section{Availability of data and materials}

The single institute data from this study is available from the corresponding author upon reasonable request.

\section{Declarations}

\section{Ethical approval and consent to participate}

The study was approved by the Ethics Committee of the First Affiliated Hospital, College of Medicine, Zhejiang University (2020IIT 748th). Informed written consent was obtained from the patient for the studies conducted and for publication of any potentially identifiable images or data included in this article.

\section{Consent for publication}

All authors of the manuscript have read and agreed to its content for publication

\section{Competing interests}

The authors declare no competing financial interests.

\section{Author details}

${ }^{1}$ Myelodysplastic Syndromes Diagnosis and Therapy Center, Department of Hematology, The First Affiliated Hospital, College of Medicine, Zhejiang University, 79\# Qingchun Road, Hangzhou 310003, Zhejiang, China. ${ }^{2}$ Department 
of Hematology, The First Affiliated Hospital, College of Medicine, Zhejiang University, Hangzhou 310003, Zhejiang, China. ${ }^{3}$ Department of Pathology, The First Affiliated Hospital, College of Medicine, Zhejiang University, Hangzhou 310003, China. ${ }^{4}$ Department of Hematology and Hematopoietic Stem Cell Transplant Center, Zhejiang Provincial People's Hospital, Hangzhou 310014, Zhejiang, China.

Received: 18 April 2021 Accepted: 31 May 2021

Published online: 13 June 2021

\section{References}

1. Esteban YM, de Jong JLO, Tesher MS. An overview of hemophagocytic lymphohistiocytosis. Pediatric Annals. 2017;46(8):e309-13.

2. Seidel MG, Kindle G, Gathmann B, Quinti I, Buckland M, van Montfrans J, Scheible R, Rusch S, Gasteiger LM, Grimbacher B, et al. The European society for immunodeficiencies (ESID) registry working definitions for the clinical diagnosis of inborn errors of immunity. J Allergy Clin Immunol Pract. 2019;7(6):1763-70.

3. Abolhassani $\mathrm{H}$, Hammarstrom L, Cunningham-Rundles C. Current genetic landscape in common variable immune deficiency. Blood. 2020;135(9):656-67.

4. Lopez-Herrera G, Tampella G, Pan-Hammarstrom Q, Herholz P, Trujillo-Vargas CM, Phadwal K, Simon AK, Moutschen M, Etzioni A, Mory A, et al. Deleterious mutations in LRBA are associated with a syndrome of immune deficiency and autoimmunity. Am J Hum Genet. 2012;90(6):986-1001.

5. Gamez-Diaz L, August D, Stepensky P, Revel-Vilk S, Seidel MG, Noriko M, Morio T, Worth AJJ, Blessing J, Van de Veerdonk F, et al. The extended phenotype of LPS-responsive beige-like anchor protein (LRBA) deficiency. J Allergy Clinic Immunol. 2016;137(1):223-30.
6. Gamez-Diaz L, Sigmund EC, Reiser V, Vach W, Jung S, Grimbacher B. Rapid flow cytometry-based test for the diagnosis of lipopolysaccharide responsive beige-like anchor (LRBA) deficiency. Front Immunol. 2018;9:720.

7. van Schouwenburg PA, Davenport EE, Kienzler AK, Marwah I, Wright B, Lucas M, Malinauskas T, Martin HC, Lockstone HE, et al. Application of whole genome and RNA sequencing to investigate the genomic landscape of common variable immunodeficiency disorders. Clin Immunol. 2015;160(2):301-14

8. Macpherson ME, Halvorsen B, Yndestad A, Ueland T, Mollnes TE, Berge RK, Rashidi A, Otterdal K, Gregersen I, Kong XY, et al. Impaired HDL function amplifies systemic inflammation in common variable immunodeficiency. Sci Rep. 2019;9(1):9427.

9. Li J, Jorgensen SF, Maggadottir SM, Bakay M, Warnatz K, Glessner J, Pandey R, Salzer U, Schmidt RE, Perez E, et al. Association of CLEC16A with human common variable immunodeficiency disorder and role in murine B cells. Nat Commun. 2015;6:6804.

10. Mayor PC, Eng KH, Singel KL, Abrams SI, Odunsi K, Moysich KB, Fuleihan R, Garabedian E, Lugar P, Ochs HD, et al. Cancer in primary immunodeficiency diseases: cancer incidence in the United States immune deficiency network registry. J Allergy Clin Immunol. 2018;141(3):1028-35.

11. Arber DA, Orazi A, Hasserjian R, Thiele J, Borowitz MJ, Le Beau MM, Bloomfield CD, Cazzola M, Vardiman JW. The 2016 revision to the World Health Organization classification of myeloid neoplasms and acute leukemia. Blood. 2016;127(20):2391-405.

\section{Publisher's Note}

Springer Nature remains neutral with regard to jurisdictional claims in published maps and institutional affiliations.
Ready to submit your research? Choose BMC and benefit from:

- fast, convenient online submission

- thorough peer review by experienced researchers in your field

- rapid publication on acceptance

- support for research data, including large and complex data types

- gold Open Access which fosters wider collaboration and increased citations

- maximum visibility for your research: over $100 \mathrm{M}$ website views per year

At BMC, research is always in progress.

Learn more biomedcentral.com/submissions 